\title{
Quality peptide versus speed: Conventional synthesis versus microwave
}

Hossain Saneii, Farshad Karimi, William Bennett, Mandar Maduskar, Mostafa Hatam

AAPPTec, United States

https://doi.org/10.17952/35EPS.2018.104

\section{Abstract}

We have conducted studies comparing microwave heating versus conventional heating in solid phase peptide synthesis. We have found that very rapid heating, as in microwaves, speeds the rate of synthesis, but it accelerates epimerization and other undesirable reactions as well. We have compared conventional synthesis with microwave synthesis for a number of peptides. In general, conventional methodology takes $32 \%$ longer, but no epimerization occurs. Also it provides higher yield by delay gradient heating and reduces the purification difficulties.

\section{Discussion}

The following results show that not only higher quality but almost zero epimerization is obtained with room temperature or delay gradient heating even though they take more time. ACP (65-74), ABC-20 mer, bivalirudin, dynorphin A, exenatide, GPR, JR 10-mer, liraglutide, magainin I and thymosin were prepared by standard solid phase peptide synthesis at room temperatureand delayed gradient heating. The delay gradient profile began with 5 minutes at room temperature, then gradient to $65{ }^{\circ} \mathrm{C}$ for 10 to maximum 15 minutes. Fmoc deprotection was performed with delay gradient heating in $20 \%$ piperidine/DMF The delay gradient for deprotection started with 2 minutes at room temperature, then gradient heating to $55^{\circ} \mathrm{C}$ in 3 minutes.

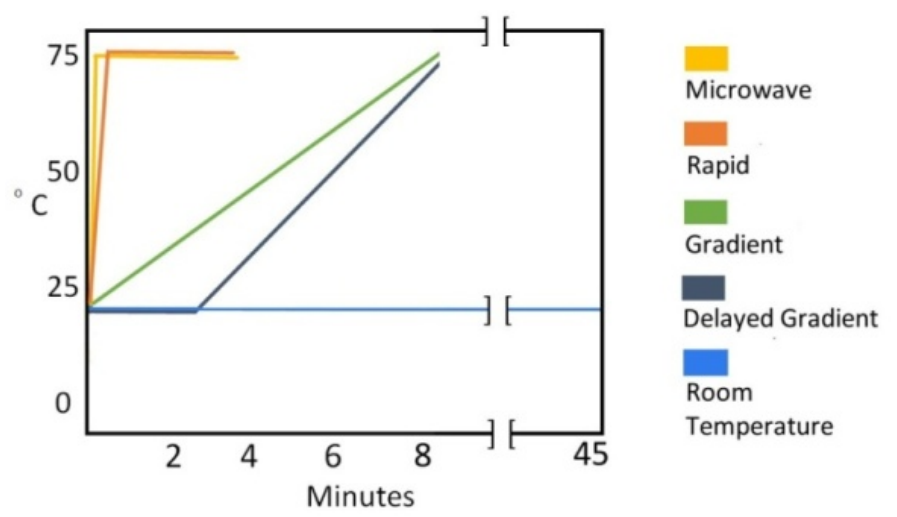

Figure 1: Comparison of Heating Methods

As an example, $\mathrm{ACP}(65-74)$ provided a quality of $95 \%$ by delay gradient heating which is close to the results obtained with microwave. HPLC of the crude ACP showed single major peak for both syntheses. However, through further investigation, crude ACP from microwave synthesis was revealed to contain an epimerization product that co-eluted with the desired peptide (Figure 2). With further purification pure ACP was obtained as a perfect single peak (Figure 4). However, the peptide produced at room temperature showed only one peak under all conditions.

The results in Table 1 show purities from $78 \%$ to $95.19 \%$. Delay gradient heating shows results better than microwave heating or room temperature synthesis. Compared to microwave synthesis, the delayed gradient protocol only increased cycle time by $32 \%$ ( 22 min per cycle). 
Table 1

\begin{tabular}{|l|l|l|}
\hline Peptide & Purity (Delay Gradient) & Mass Spectrum \\
\hline ABC-20 mer $^{\mathrm{a}}$ & $95.19 \%$ & {$[\mathrm{M}]^{+}: 1062.22$} \\
\hline ACP $(65-74)^{\mathrm{b}}$ & $95 \%$ & \\
\hline Bivaliruden $^{\mathrm{c}}$ & $90.75 \%$ & \\
\hline Dynorphin Ad $^{\mathrm{d}}$ & 91.75 & {$[\mathrm{M}+\mathrm{Na}]^{+}: 123.6$} \\
\hline JR 10-mer & $91.22 \%$ & \\
\hline Magainin I & $78 \%$ & \\
\hline Thymosin' $^{\mathrm{i}}$ & & \\
\hline
\end{tabular}

Crude Peptides

a) Sequence: VYWTSPFMKLIHEQCNRADG-NH 2 ; b) Sequence: VQAAIDYING-NH $\mathrm{N}_{2}$; c) Sequence: fPRPGGGGNGDFEEIPEEYL; d) Sequence: YGGFLRRIRPKLKDNQ; e) Sequence: WFTTLISTIM - $\mathrm{NH}_{2}$; f) Sequence: HAEGTFTSDVSSYLEGQAAK( $\gamma$-Glu-palmitoyl)EFIAWLVRGRG; i) Sequence: GIGKFLHSA GKFGKAFV GEIMKS; j) Sequence: SDAAVDTSSEITTKDLKEKKEVVEEAEN

General Procedure

All peptides were synthesized on a Focus XC 2RV or a Focus XC 6RV from AAPPTec, LLC. Both instruments were equipped with heating capabilities. Each synthesis was performed on $100 \mathrm{mg}$ of Rink amide resin with a substitution of $0.5 \mathrm{mmol} / \mathrm{g}$. Fmoc-protecting groups were removed utilizing a $20 \%$ piperdine in DMF solution containing $0.2 \mathrm{M}$ Oxyma Pure. The resin was washed with DMF to less than $0.02 \%$ piperidine using two or a single wash.

Couplings reactions were conducted utilizing 3 equivalents of amino acid, 3 equivalents of diisopropylcarbodiimide (DIC), and 3 equivalents of Oxyma Pure. The difficulty of each coupling was predicted using an algorithm we developed. Extended coupling times and double couplings were utilized based on this assessment (Figure 3). The crude peptides were analyzed by HPLC and the identity of the crude peptides was confirmed by mass spectroscopy/HPLC. (Table 1)

\# 13

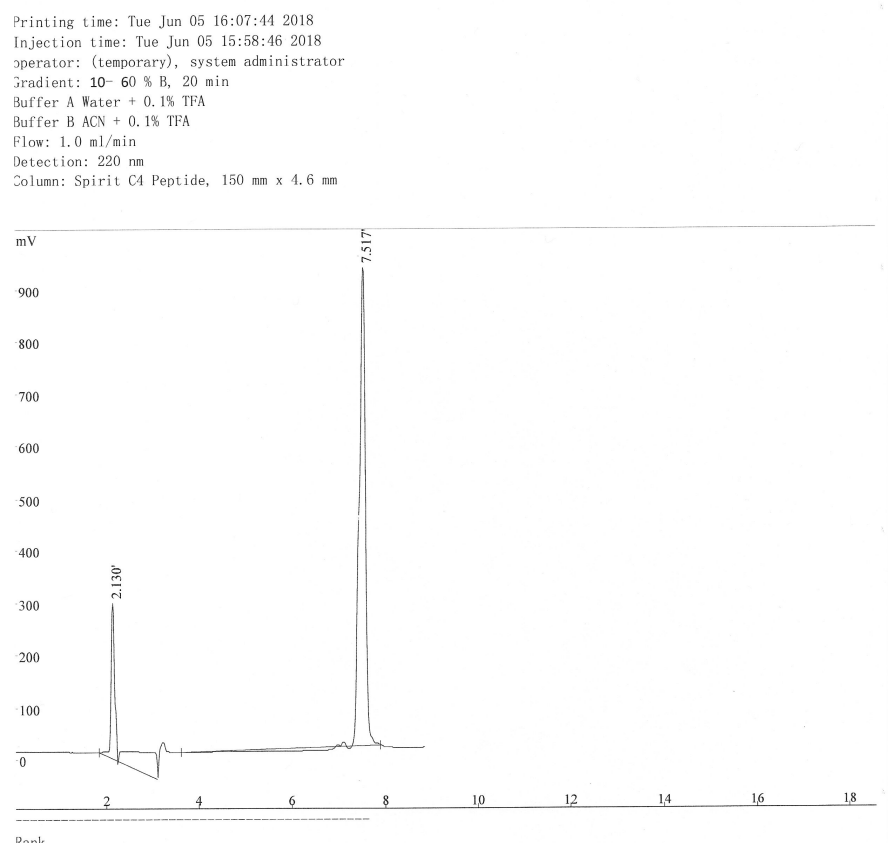

Figure 2: ACP Crude from Delayed Gradient 
\#7

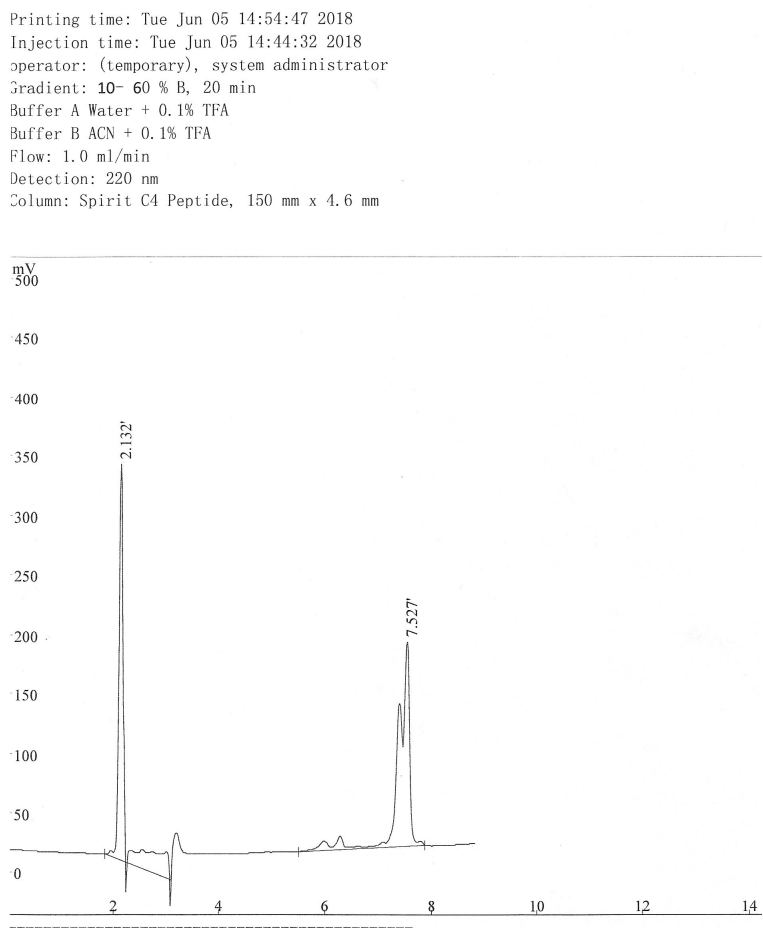

Figure 3: ACP Modified Conditions

\section{ACP Sample}

Printing time: Tue Jun 05 10:48:43 2018

Injection time: Tue Jun 05 10:30:35 2018

sperator: (temporary), system administrator

aradient: 10- $60 \% \mathrm{~B}, 20 \mathrm{~min}$

Flow: $1.0 \mathrm{ml} / \mathrm{min}$

Detection: $220 \mathrm{~nm}$

Column: Spirit C4 Peptide, $150 \mathrm{~mm} \times 4.6 \mathrm{~mm}$

$\mathrm{mV}$

2700

2400

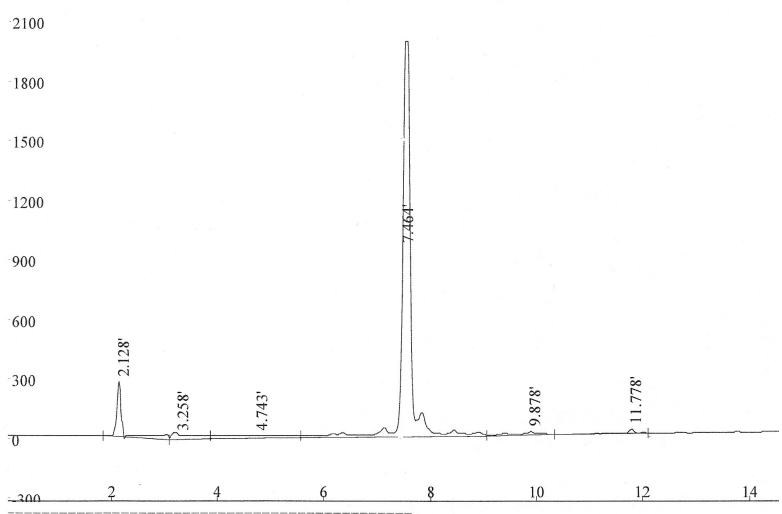

Figure 4: Purified ACP

\section{Conclusions}

Peptide synthesis with delay gradient heating produces better quality peptide than microwave heating. Delay gradient heating takes more time (22 minutes per cycle), but the improved quality of the crude peptide with little or no epimerization results in less time spent in purification. 